\title{
Control and Investigation of Operational Characteristics of Variable Speed Wind Turbines with Doubly Fed Induction Generators
}

\author{
Abdelali AARIB*, Aymane EL MOUDDEN, \\ Abdelhadi EL MOUDDEN and Abdelhamid HMIDAT
}

\author{
Team Energy \& Conversion, Laboratory of Energy \& Electrical Systems, The National Graduate School \\ of Electricity and Mechanics (ENSEM), University Hassan II, Casablanca, Morocco
}

('Corresponding author's e-mail: aliaarib@gmail.com)

Received: 3 July 2020, Revised: 13 October 2020, Accepted: 23 November 2020

\begin{abstract}
This article deals with the analysis, modeling, and control of the doubly-fed induction generator (DFIG) for wind turbines. The DFIG wind turbine can deliver more energy to the grid. There are some different methods to modify the DFIG system in order to accomplish the stator reactive power proposed. One of these methods is to modify the DFIG system for nominal voltage to evaluate cost and materialsefficiency consequences. A specific control strategy is implemented according to the vector control strategy. The proportional-integral (PI) regulators used are simple and precise controllers. This type of regulation, which is closed-loop rotor currents, allows adjustment of the sliding of the DFIG. This gives a good adjustment of the powers of the stator and the rotor. The percentage error of the simulation is less than $2 \%$. The results obtained in these investigations show that it is possible to adjust the powers of the stator, even with a variation of the parameters. The developed method will allow achieving the maximum efficiency of the wind energy conversion chain. The objective of this article is to optimize the quality of energy generated by wind turbines by controlling the reactive stator power and reducing the losses of the energy of the reactive stator power, which must be a physically minimal value. The results will be presented in the Matlab - Simulink environment.
\end{abstract}

Keywords: Generator, DFIG, Materials-efficiency, Simulation, Matlab-Simulink

\section{Introduction}

Wind energy systems have experienced substantial growth in recent years, and there is an increase in the interest in the doubly-fed induction generator (DFIG), especially in the field of renewable energy. Indeed, in the wind energy area, the DFIG has many advantages. Additionally, the converter linked to the rotor armature is sized to a third of the rotor's rated power, which reduced the losses in the semiconductor costs. Currently, most wind turbines are equipped with DFIG. This is due to several advantages. One of these advantages is that the power variable speed generation $( \pm 30 \%$ around the synchronous speed $)$ allows operation over a wide range of wind speeds and derive the maximum possible power for each wind speed. This is the principle of maximum Power Point Tracking (MPPT) [1]. Today, studies turn on the improvement of the aerogenerator as well as on the conversion chain of wind energy into electric energy, which can be exploited by the grid. The first wind turbines implement an asynchronous generator, which is linked to the vanes via a gearbox, work at a fixed speed, and are directly connected to the grid. The most recent systems are inclined towards the variable speed in order to maximize the power picked up from the wind with the insertion of electronics between the generator and the grid. The technique of vectorial control is based on a law of control leading to a characteristic of setting, which is similar to that of a machine with a continuous current operating with a separate excitement [2]. In the case of the 
http://wjst.wu.ac.th

vectorial control of the DFIG, the task will be to master energy exchanges and notably the active and reactive power transfers sent on the grid. In this study, the referential (DQ) is adjusted on stator flux and the control concerns sent the powers on the grid on the side of the stator (generator Convention). Consequently, the rotor will be considered a control tool (receptor convention) [3]. However, the coupling existing between the electric variables and parameters makes the control very difficult. To overcome these problems, we adopt vectorial control [4]. It is possible to solve this problem using nonlinear control methods, notably the control with the orientation of stator flux. Also, in order to improve the previous control, an indirect control will be introduced so that the control will be performed in a linear way by controlling the stator powers and the rotor currents separately [5].

\section{Materials and methods}

Figure 1 shows the coordinated reactive power controller, which was designed to consider the rotor side converter (RSC) as the main controller with the grid side converter (GSC) acting as the auxiliary controller (50\% converter rating). These are the coordinated control scheme between the GSC and RSC [6]. The RSC reactive power capability $\left(Q_{c c}\right)$ is determined based on the capability, while considering the total active power output $\left(\mathrm{P}_{\mathrm{m}}\right)$ and operating slip $(\mathrm{S})$ of the DFIG. Then, $\mathrm{Q}_{c c}$ is compared against the reactive power reference of the DFIG system. The excess reactive power requirement becomes the reactive power reference for the $\mathrm{RSC}\left(\mathrm{Q}_{\mathrm{ref}}\right)$. Therefore, the GSC is operated at unity power factor; otherwise, the reactive power requirement exceeds the RSC reactive capability. The reactive power reference is determined based on the control strategy of the DFIG. The present study is determined based on the multi-objective control schemes presented [7]. The reactive power reference is used as the reactive power reference for the RSC, since the RSC displays higher reactive power capability over the GSC, which is selected as the main reactive power controller for the proposed control scheme. Furthermore, the RSC reactive power capability is highly dependent on the operating slip of the machine. Hence, it can provide much enhanced reactive power performance during variable speed operation (i.e. variable slip) compared to the GSC [8]. The command of the DFIG (Doubly Fed Induction Generator) by the rotor currents plays a key role in controlling the active and reactive powers of the stator. Thus, the concept of control is based on precise control of closed-loop rotor currents. Likewise, the implementation of this command facilitates the introduction of an energy generator in the wind turbine with the possibility of working in a power loop, which is represented at the control of the DFIG. The simulation and the results obtained were performed using Matlab-Simulink.

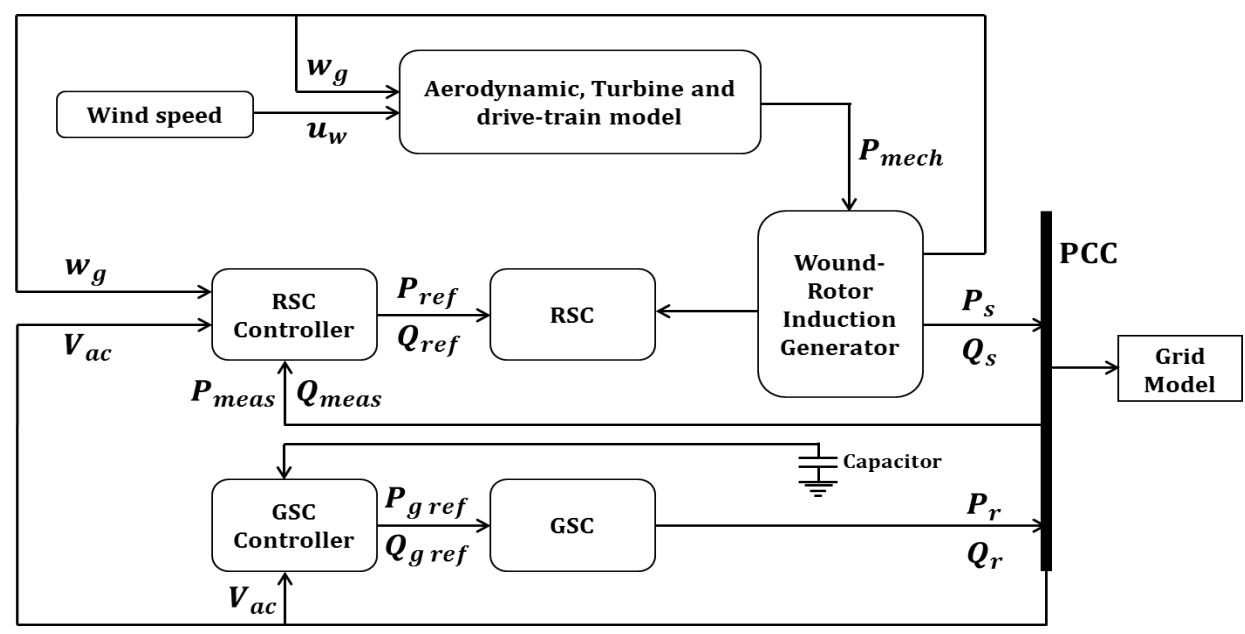

Figure 1 DFIG control model (Representation Developed By MATLAB-SIMULINK and Discussions). 
http://wjst.wu.ac.th

Figure 2 shows a variable pitch control that can be used to shed the aerodynamic power generated by the wind turbine. Thus, the aerodynamic power produced by the wind turbine can be controlled by adjusting the pitch angle of the wind turbine [9].

Figure 3 shows the effect of pitch control on power flow in wind turbine generation. With pitch control, the power captured from the wind power can be controlled by a pitch actuator [10]. The acceleration and deceleration are the result of the difference between the input power to the generator and the aerodynamic power captured by the wind turbine [11]. The transfer function and the gain value allow to command the blade of wind turbine.

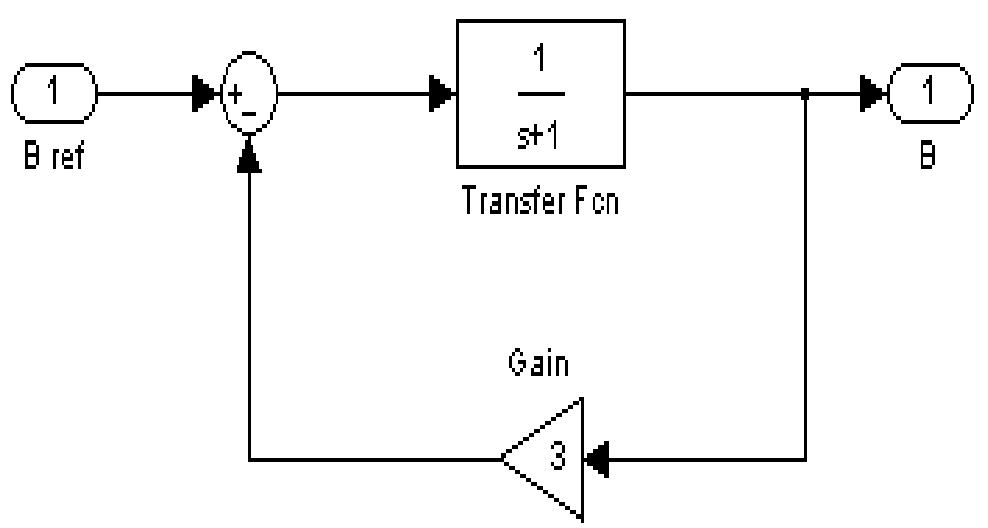

Figure 2 Regulation of the pitch angle developed in Matlab-Simulink.

\section{Application of the DFIG Control}

The DFIG is connected to an existing grid. This connection must be done in 3 steps. The first step is the regulation of the stator voltages with the network voltages as reference [12]. The second step is the stator connection to this grid. As the voltages of the 2 devices are synchronized, this connection can be done without problem $[13,14]$. Once this connection is achieved, the third step is the transit power regulation between the stator and the grid $[15,16]$. To achieve a stator active and reactive power vector control, we choose a d-q reference-frame synchronized with the stator flux by setting null the quadratic component of the stator flux:

\begin{tabular}{cl} 
RSC & Rotor Side Converter \\
\hline GSC & Grid Side Converter \\
\hline$P_{S}$ & Active power output from stator $(\mathrm{W})$ \\
\hline$Q_{s}$ & Reactive power output of stator $(\mathrm{VAR})$ \\
\hline$V_{d c}$ & DC link voltage $(\mathrm{V})$ \\
\hline$\Phi_{d s}$ & The stator flux following axis $\mathrm{d}(\mathrm{Wb})$ \\
\hline$\Phi_{q s}$ & The stator flux following axis $\mathrm{q}(\mathrm{Wb})$ \\
\hline$P$ & The number of pole pairs \\
$B_{r e f}$ & Blade pitch angle reference $($ Degree \\
\hline$B$ & Blade pitch angle (Degree) \\
\hline$L_{m}$ & Magnetizing inductance $(\mathrm{H})$ \\
\hline$L_{s}$ & Stator inductance $(\mathrm{H})$ \\
$V_{d s}$ & The stator voltage following axis $\mathrm{d}(\mathrm{V})$ \\
$V_{q s}$ & The stator voltage following axis $\mathrm{q}(\mathrm{V})$
\end{tabular}




\begin{tabular}{|c|c|}
\hline$I_{d r}$ & The rotor current following axis $d(A)$ \\
\hline$Q_{c c}$ & Rotor side converter reactive power capability (VAR) \\
\hline$P_{m}$ & Active power output (W) \\
\hline$Q_{\text {ref }}$ & Reactive power reference for the RSC (VAR) \\
\hline$I_{q r}$ & The rotor current following axis q (A) \\
\hline$I_{d s}$ & Stator current following axis d (A) \\
\hline$\omega_{s}$ & Stator pulsation $(\mathrm{rad} / \mathrm{s})$ \\
\hline$V_{r d}$ & Rotor voltage following the direct axis $(\mathrm{V})$ \\
\hline$V_{r q}$ & Rotor voltage following the quadrature axis (V) \\
\hline$\Phi_{s}$ & Stator flux $(\mathrm{Wb})$ \\
\hline$V_{s}$ & Stator voltage $(\mathrm{V})$ \\
\hline$P_{s \text { meas }}$ & Stator active power measured (W) \\
\hline$Q_{s \text { meas }}$ & Stator reactive power measured (VAR) \\
\hline$\omega_{g}$ & Generator shaft speed $(\mathrm{rad} / \mathrm{s})$ \\
\hline$u_{w}$ & Wind speed $(\mathrm{m} / \mathrm{s})$ \\
\hline$P_{r}$ & Active power output from rotor $(\mathrm{W})$ \\
\hline$Q_{r}$ & Reactive power output of rotor (VAR) \\
\hline$P_{\text {gref }}$ & Active power reference of GSC (W) \\
\hline$P_{\text {mech }}$ & Mechanical power input to the generator (W) \\
\hline PCC & The point of common coupling \\
\hline$S$ & Slip \\
\hline$Q_{\text {gref }}$ & Reactive power reference of GSC (VAR) \\
\hline$P_{g c}$ & Power transfer through the GSC (W) \\
\hline$Q_{g c}$ & Reactive power capability of GSC (VAR) \\
\hline$P_{\text {smes }}$ & Active power output from stator measured (W) \\
\hline$Q_{\text {smes }}$ & Reactive power output of stator measured (VAR) \\
\hline$P_{\text {s ref }}$ & Active power output from stator of reference $(\mathrm{W})$ \\
\hline$Q_{\text {sref }}$ & Reactive power output of stator of reference (VAR) \\
\hline
\end{tabular}

Then the couple is simplified into:

$C_{e m}=-p \frac{L_{m}}{L_{s}} I_{q r} \Phi_{s}$

In order to calculate angles from the Park transformation for stator and rotor variables, the stator pulsation and the mechanical speed must be determined. By choosing this reference frame, stator voltages and fluxes can be rewritten as follows:

$\mathrm{V}_{\mathrm{ds}}=0$

$\mathrm{V}_{\mathrm{qs}}=\mathrm{V}_{\mathrm{s}}=\mathrm{W}_{\mathrm{s}} \phi_{\mathrm{s}}$

$\phi_{\mathrm{ds}}=\phi_{\mathrm{s}}=\mathrm{L}_{\mathrm{s}} \mathrm{I}_{\mathrm{ds}}+\mathrm{L}_{\mathrm{m}} \mathrm{I}_{\mathrm{dr}}$ 


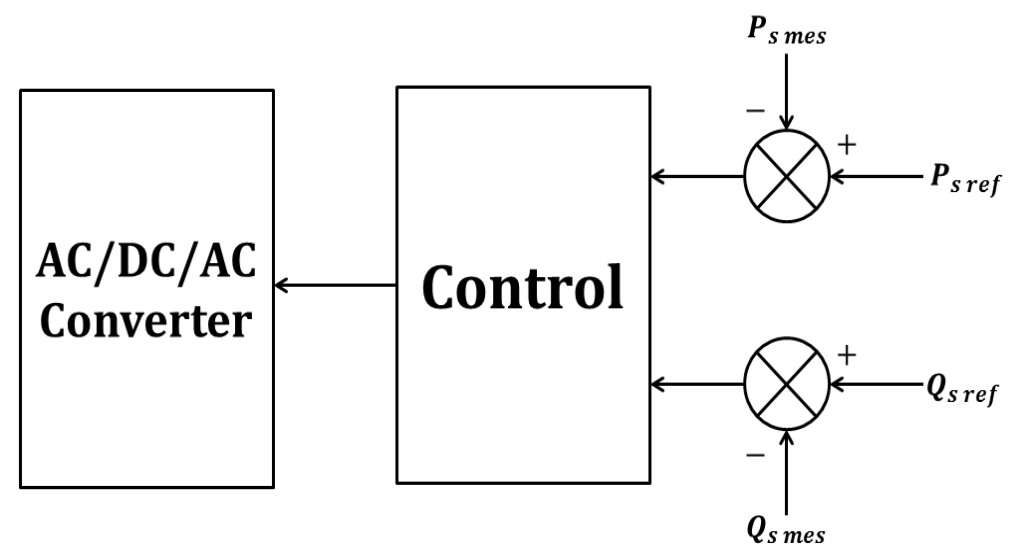

Figure 3 Power control of DFIG.

The industrial problem of wind turbines is that it is very difficult to reach an almost Unitarian optimal power factor. The objective of the new command synthesized in this work is to return the value of the stator reactive power less at any weather conditions. The vector control orientation of the flow has an attractive solution to achieve better performance in variable speed applications in case the DFIG is either under operation generator or motor. In this context, we proposed a control law for DFIG based on the orientation of the stator flux used to run a generator. The latter highlights the relationship between the stator and rotor ingredients $[17,18]$. These relationships will help to act on the rotor signals to control the exchange of active and reactive powers between the stator of the machine and the grid with a constant and directed stator flux $\phi_{\mathrm{sd}}=\phi_{\mathrm{s}}$ and $\phi_{\mathrm{sq}}=0$. If we neglect the resistance of the stator windings, the equations of the tensions of the machine are reduced to the following form (Figure 4). The wind turbine is connected to the DFIG through a mechanical shaft system, which consists of a low and a high-speed shaft with a gearbox in between $[19,20]$. The wound rotor induction machine in this configuration is fed from both stator and rotor sides. The stator is directly connected to the grid; while the rotor is connected to the grid through power converters. In order to produce electrical power at constant voltage and frequency to the utility grid for a wide operating range from sub synchronous to super synchronous speeds, the power flow between the rotor circuit and the grid must be controlled both in magnitude and in direction. Therefore, the power converters consists of two four-quadrant insulated-gate bipolar transistor (IGBT) pulse width modulation (PWM) converters connected back-to back by a dc-link capacitor [21]. The crowbar is used to short circuit the rotor side converter in order to protect it from over current in the rotor circuit during transient grid disturbances [22]. The Control of the DFIG is achieved by control of the converters, which includes control of the RSC and control of the GSC. The objective of the RSC is to independently regulate the stator active and reactive powers, which are represented by $P_{S}$ and $Q_{s}$ respectively [23]. The reactive powers control using the RSC can be applied to keep the stator voltage $\mathrm{V}_{\mathrm{s}}$ within the desired range when the DFIG feeds into a weak power system without any local reactive compensation. When the DFIG feeds into a strong power system, the command of $\mathrm{Q}_{\mathrm{s}}$ shows the overall vector control scheme of the RSC in order to achieve independent control of the stator active powers $\mathrm{P}_{\mathrm{S}}$ and $\mathrm{Q}_{\mathrm{s}}[24,25]$. 
http://wjst.wu.ac.th

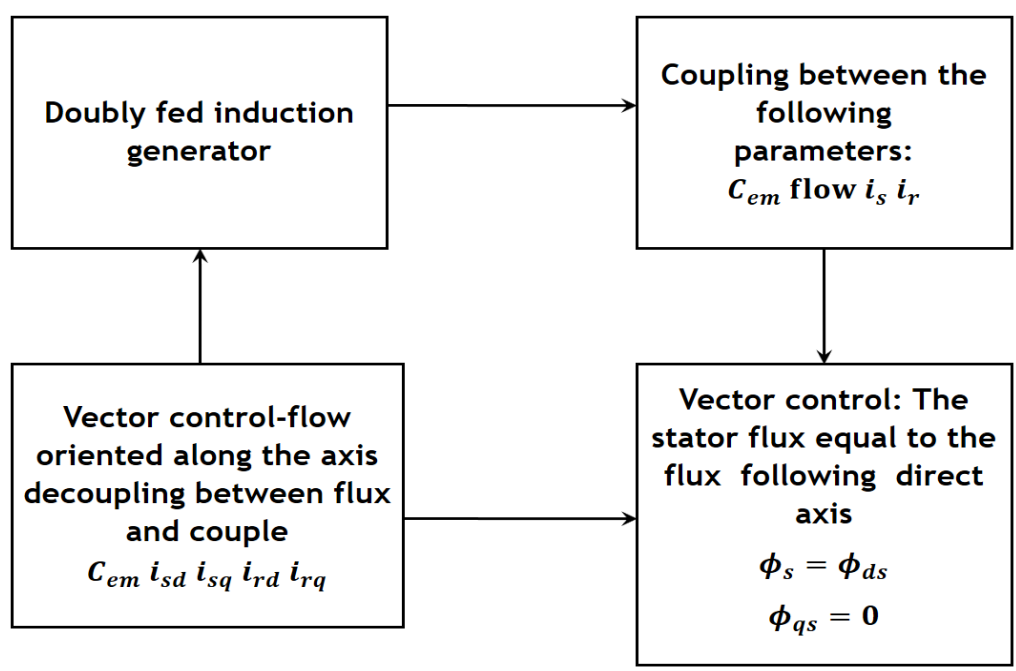

Figure 4 Vector control of DFIG.

Figure 5 shows the 3-phase voltage regulation by pulse width modulation to extract the maximum from the stator active power and the minimum reactive stator power injected into the grid developed by Matlab-Simulink [26,27].

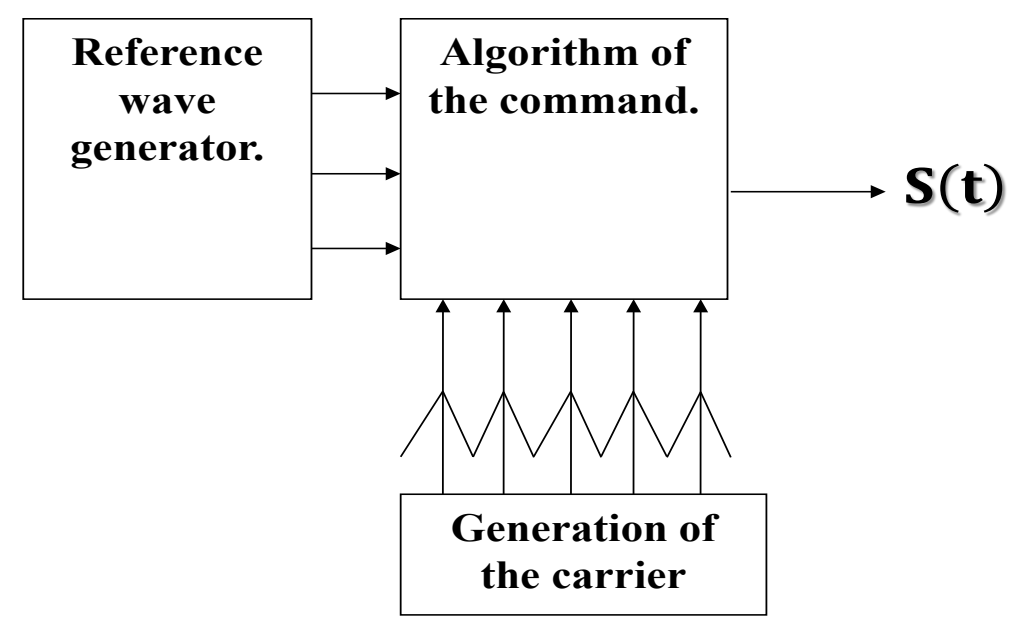

Figure 5 PWM control of injected reference rotor tensions in converters.

Table 1 shows the parameters of the machine of the DFIG, which is used in wind energy. The technique of vectorial control is based on a law of control leading to a characteristic of setting, which is similar to that of a machine with a continuous current operating with a separate excitement. In the case of the vectorial control of the DFIG [28], the task will be to master energy exchanges and notably the active and reactive power transfers sent on the grid [29]. To improve the command, we introduce an algorithm of the indirect command of the active and reactive powers of the DFIG [30], according to the rotor 
http://wjst.wu.ac.th

current. Hence, the terms of coupling considered as being important disturbances [31,32], and must be compensated. The command, so decoupled, is realized by using proportional integral regulators (PI) [33]. There are 2 methods of decoupling in opened loop and in closed loop to control the stator powers [34,35].

Table 1 Parameters of the machine.

\begin{tabular}{cc}
\hline Parameters & Values \\
\hline Nominal Power & $2.5 \mathrm{MW}$ \\
Nominal Voltage & $660 \mathrm{KV}$ \\
Nominal Frequency & $50 \mathrm{~Hz}$ \\
Stator Inductance & $0.0067 \mathrm{H}$ \\
Rotor Inductance & $0.0065 \mathrm{H}$ \\
\hline
\end{tabular}

\section{Results and discussion}

These results concurred with the experimental findings in experimental prototypes of the curves. They remain reliable as long as the electricity grid is stable in tension and frequency. The observations of these results are different from previous studies. This command of the electrical parameters of wind turbine energy using a doubly-fed induction machine injected into the grid regulates an error on the active and reactive stator powers' instructions.

Figure 6 shows that the electromagnetic couple depends on the variation of the rotor currents. It is independent from the speed of wind and it varies between $(0$ N.m) and $(2750$ N.m). It also depends from the rotor current $\boldsymbol{i}_{\boldsymbol{q}}$.

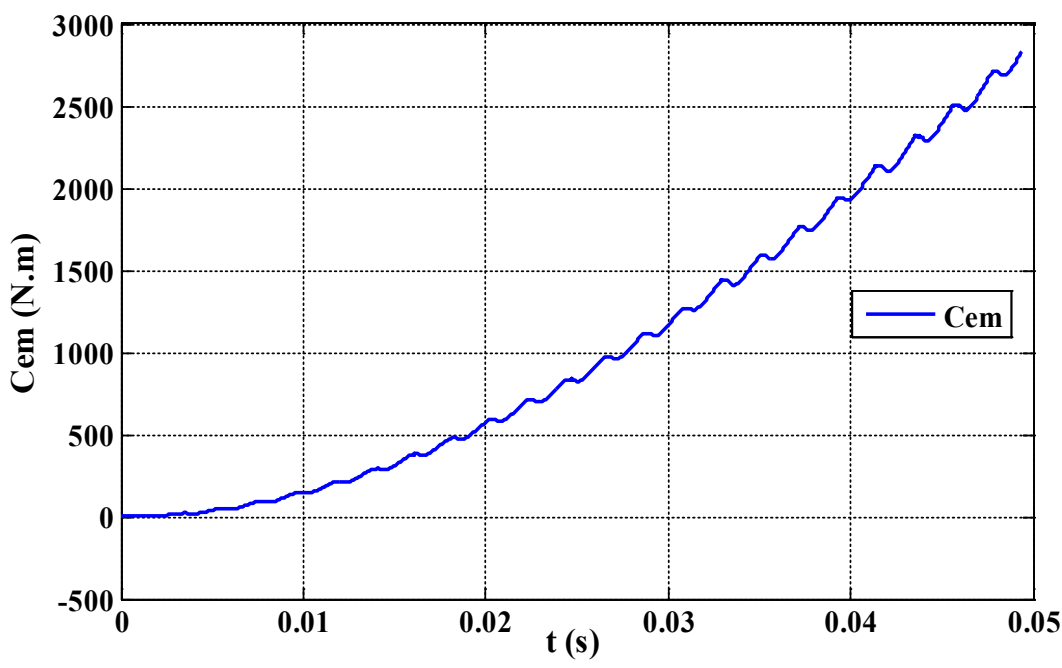

Figure 6 Electromagnetic couple $\boldsymbol{C}_{\boldsymbol{e m}}$ (N.m) according to time (s). 
http://wjst.wu.ac.th

Figure 7 shows the stator currents, which depends on the variation of the stator active power and the stator reactive power of the machine. These forms of waves depend on the speed of the rotation of the machine as well as on the rotor power according to the absorption or the supply. These curves vary in as sinusoidal way, and the value of this curves reached (-290 A) and (210 A).

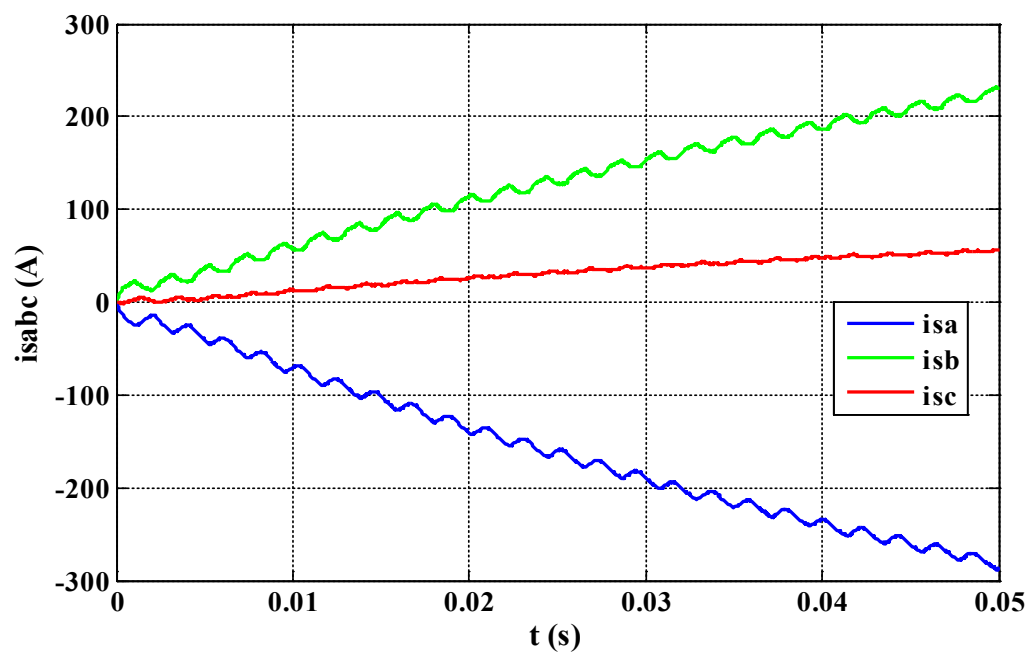

Figure 7 Stator currents isabc (A) according to time (s).

Figure 8 shows the rotor current is influenced by the variation of the reactive stator current absorbed by the DFIG. These currents ira (A), irb (A) and irc (A) vary approximately between (-1500A) and $(+1500 \mathrm{~A})$. They are independent on the profile of wind speed. The rotor currents depend on the variation of the speed of asynchronous machine with double feeding, and on the variation of the sliding of the machine according to the absorption or the supply of the rotor power.

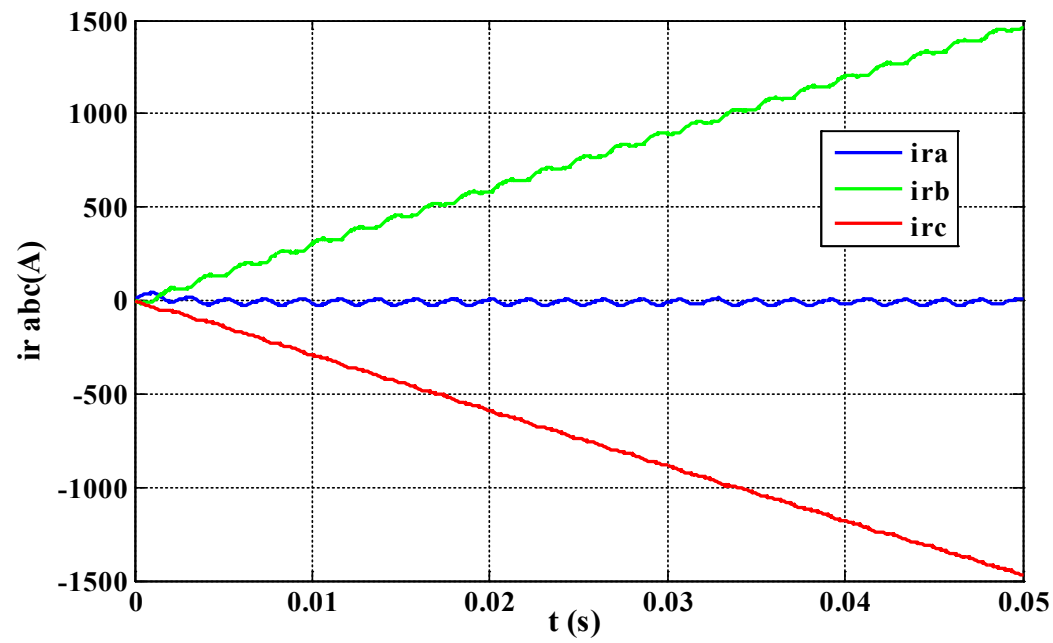

Figure 8 Rotor current irabc (A) according to time (s). 
http://wjst.wu.ac.th

Figure 9 shows the evolution of rotor currents. These wave forms depend on the speed of the wind. The currents irq (A) and ird (A) vary between $(-1700 \mathrm{~A})$ and $(+0 \mathrm{~A})$, and these are independent from the profile of wind turbine. These values show that the systems are adapted to high power wind turbine. These currents depend on the active and reactive power.

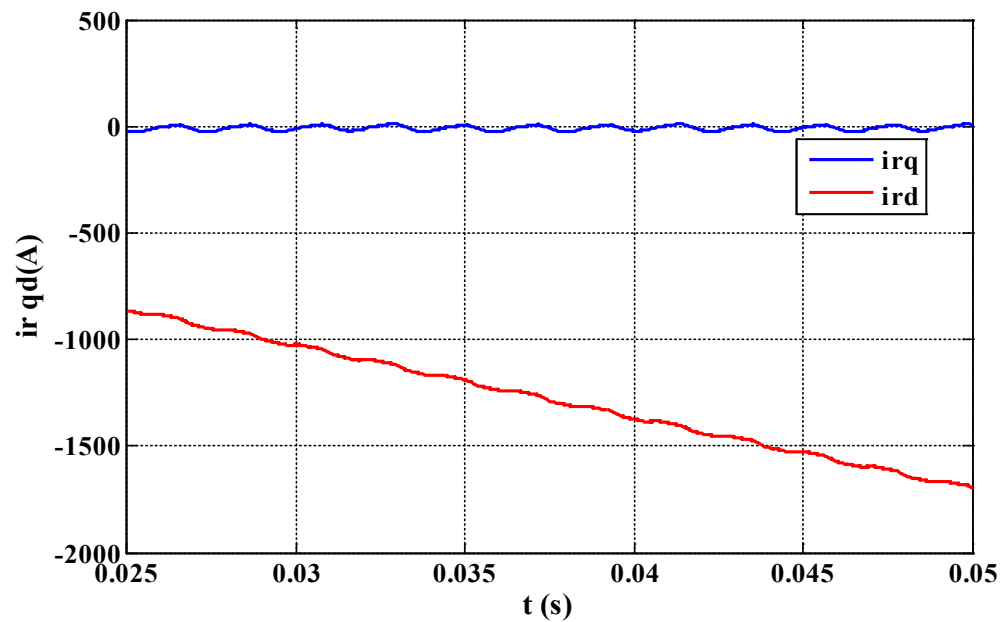

Figure 9 Rotor current irq (A), ird (A) according to time (s).

Figure 10 shows the wave of stator currents, which are linked to that of the stator active powers and of the stator reactive powers. These currents vary in sinusoidal forms. We can remark that the currents vary in a sinusoidal manner by increasing their amplitudes. The values of these curves vary on (-100A) to (-290A). These curves depend on the stator flux and stator voltage.

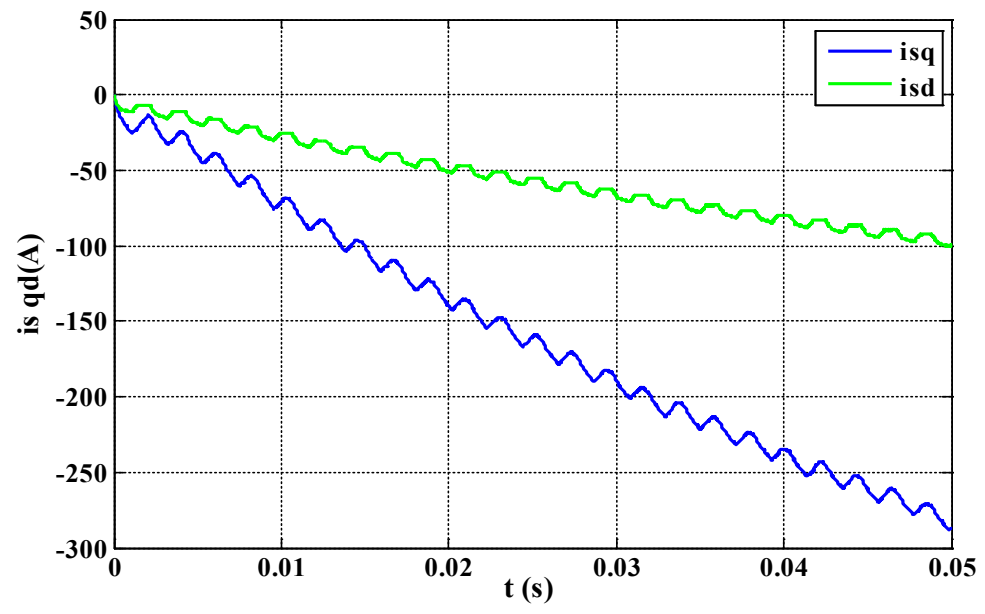

Figure 10 Stator current isq (A), isd (A) according to time (s). 
http://wjst.wu.ac.th

Figure 11 shows the active stator powers, which depend on the variation of the stator currents, of the machine and of the sliding of the machine. It varies between $(-25 \mathrm{KW})$ and $(25 \mathrm{KW})$. The Ps differs largely from Ps ref because in our case the Ps ref is to regulate more Ps. These kinds of machine can reach high value, which is adapted to high power wind turbine, and the simulation time is $0.05 \mathrm{~s}$. The value can reach the nominal power using the control of the DFIG according to the energy requirement. Lastly, the optimal value of stator power can go up to $2.5 \mathrm{MW}$.

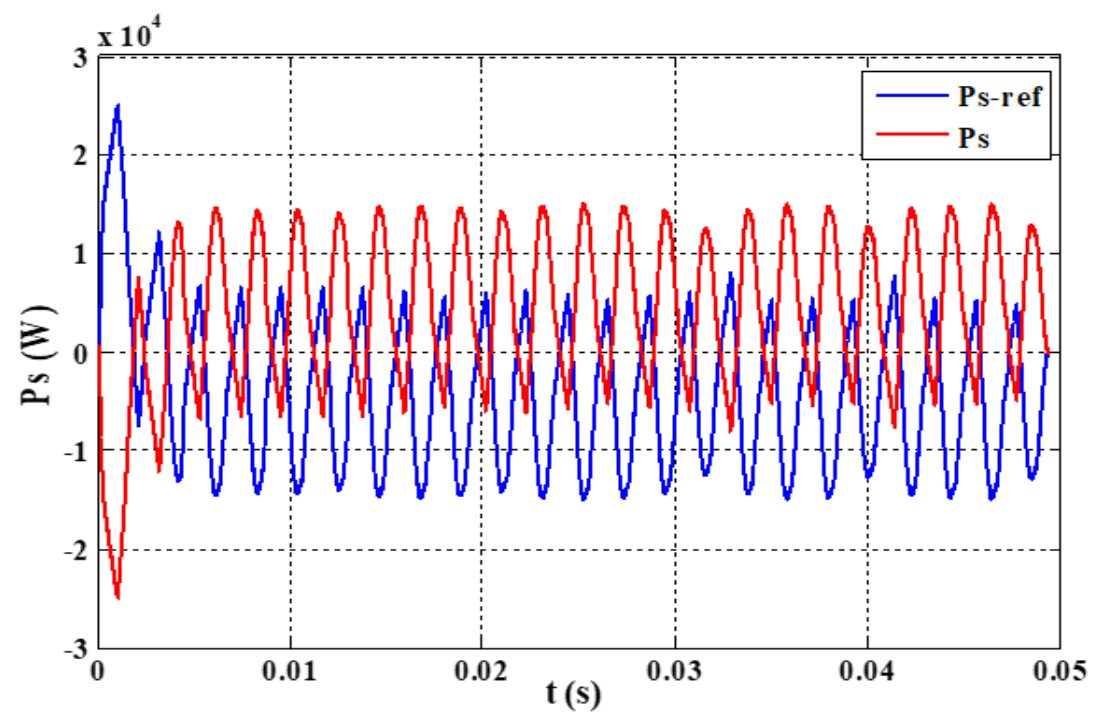

Figure 11 Stator active powers Ps (W) according to time (s).

Figure 12 shows the robustness of the indirect control of the asynchronous machine with double feeding. Since it has lesser values, it allows the diminution of the losses on the grid as well as the increase in the power factor, which is good for the optimization of the energy which is injected in the grid. The reactive stator power is in the order of $-5 \mathrm{VAR}$. The value of reactive power is negative because the generator mode and the machine produce energy, which absorbs the reactive energy.

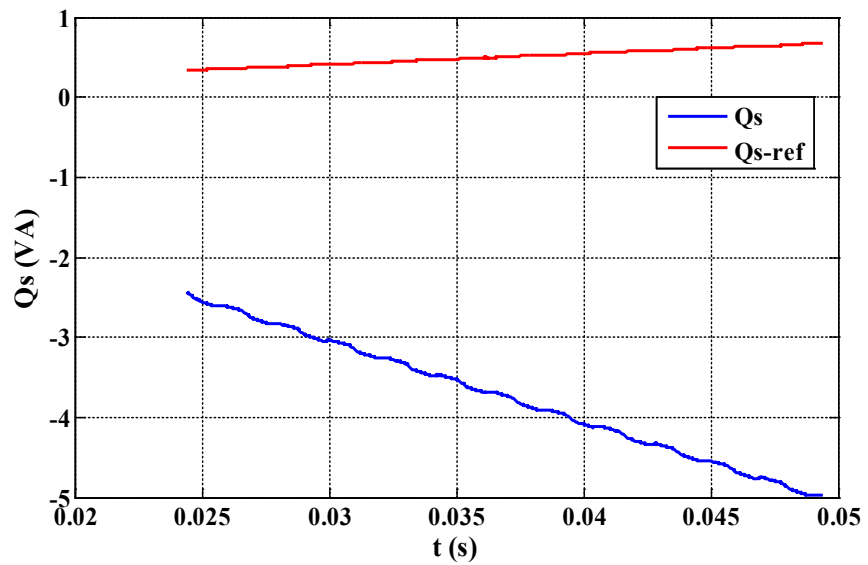

Figure 12 Reactive stator power Qs (VAR) according to time (s). 
http://wjst.wu.ac.th

\section{Conclusions}

We have studied the behavior of the asynchronous machine with double feeding. Currently, most of the wind turbines are equipped with DFIG due to several advantages. These advantages include the power variable speed generation ( $\pm 30 \%$ around the synchronous speed), which allows the operation over a wide range wind speeds, and derive the maximum possible power for each wind speed. This is the principle of maximum Power Point Tracking (MPPT). The use of DFIG allows the decoupled control of active and reactive power, reducing losses, mechanical stress and improving the acoustic noise and the quality of the power produced. When we apply the command, this one remains robust and suitable for a DFIG used in the wind energy. This has been deduced from previously completed simulation results. The modeling of the asynchronous generator inspired us with double feeding in order to apply a separate control of active and reactive powers. The solution involves numerous advantages on the technical and economic levels, especially with regard to configurations based on cage asynchronous machine and synchronous machine. The control design is discussed and the controller performance for power strategies has been treated and tested by Matlab-Simulink. The algorithm based on a traditional (PI) controller can be used under every circumstance without variations on the actual wind generators' control hardware. The method demonstrated that it can be used for any DFIG used in a wind turbine energy. In addition, the approach makes it possible to optimize the quality of the installation's energy and, therefore, obtain better performances. The command shows a new result by finding stator reactive power, which reduces energy losses. It can be used to implement and develop various studies such as interaction of wind farm with an energy storage system, interaction of model with a solar system, applying protection system technology and developing new advanced control schemes. From the results obtained, we can conclude that the use of the command is well adapted to the kind of systems. We based our work on the doubly fed induction generator model in order to apply a separate control of active and reactive powers. The results have been presented in Matlab-Simulink.

\section{Acknowledgements}

This article is produced in the Laboratory of energy and electrical systems (LESE). Team Energy \& Conversion - National School of Electricity and Mechanics Casablanca Morocco. I want to thank very much Mr. Abdelhadi EL MOUDDEN, my research director.

\section{References}

[1] E Hamatwi, I Davidson, MN Gitau and G Adam. Modeling and control of voltage source converters for grid integration of a wind turbine system. In: Proceedings of the 2016 IEEE PES PowerAfrica, Livingstone, Zambia, 2016.

[2] H Liu and Z Chen. Contribution of VSC-HVDC to frequency regulation of power systems with offshore wind generation. IEEE Trans. Energ. Convers. 2015; 30, 918-26.

[3] B Singh and SR Arya. Adaptive theory-based improved linear sinusoidal tracer control algorithm for DSTATCOM. IEEE Trans. Power Electron. 2013; 28, 3768-78.

[4] YF Wang and N Chen. Impact of WRIG and DFIG wind generation ramping down on independent power systems. In: Proceedings of the 2009 IEEE PES/IAS Conference on Sustainable Alternative Energy (SAE), Valencia, Spain, 2009.

[5] UK Kalla, B Singh, SS Murthy, C Jain and K Kant. Adaptive sliding mode control of standalone single-phase microgrid using hydro, wind and solar PV array based generation. IEEE Trans. Smart Grid. 2018; 9, 6806-14.

[6] Z Wu, W Gao, X Wang, M Kang, M Hwang, YC Kang, V Gevogian and E Muljadi. Improved inertial control for permanent magnet synchronous generator wind turbine generators. IET Renew. Power Generat. 2016; 10, 1366-73.

[7] RL Sellick and M Åkerberg.Comparison of HVDC Light (VSC) and HVDC Classic (LCC) site aspects, for a $500 \mathrm{MW} 400 \mathrm{kV}$ HVDC transmission scheme. In: Proceedings of the $10^{\text {th }}$ IET International Conference on AC and DC Power Transmission, Birmingham, UK, 2012. 
http://wjst.wu.ac.th

[8] JL Elizondo, A Olloqui, M Rivera, ME Macias, O Probst, OM Micheloud and J Rodriguez. Modelbased predictive rotor current control for grid synchronization of a DFIG driven by an indirect matrix converter. IEEE J. Emerg. Sel. Top. Power Electron. 2014, 2, 715-26.

[9] J Ruddy, R Meere and T O'Donnell. Low Frequency AC transmission as an alternative to VSCHVDC for grid interconnection of offshore wind. In: Proceedings of the 2015 IEEE Eindhoven PowerTech, Eindhoven, Netherlands, 2015.

[10] A Raza, X Dianguo, S Xunwen, L Weixing and BW Williams. A novel multiterminal VSC-HVdc transmission topology for offshore wind farms. IEEE Trans. Ind. Appl. 2017; 53, 1316-25.

[11] Z Wang, J Wang, Chen, MM Begovic and Y He. MPC-based voltage/var optimization for distribution circuits with distributed generators and exponential load models. IEEE Trans. Smart Grid. 2014; 5, 2412-20.

[12] C Schmuck, F Woittennek, A Gensior and J Rudolph. Feed-forward control of an HVDC power transmission network. IEEE Trans. Contr. Syst. Tech. 2014; 22, 597-606.

[13] H Nian, P Cheng and ZQ Zhu. Coordinated direct power control of DFIG system without phaselocked loop under unbalanced grid voltage conditions. IEEE Trans. Power Electron. 2016, 31, 2905-18.

[14] AG Peter and KA Saha. Power losses assessments of LCC-based HVDC converter stations using datasheet parameters and IEC 61803 STD. In: Proceedings of the 2018 International Conference on the Domestic Use of Energy (DUE), Cape Town, South Africa, 2018.

[15] K Musasa, N Nwulu, MN Gitau and R Bansal. Review on DC collection grids for offshore wind farms with high-voltage DC transmission system. IET Power Electron. 2017; 10, 2104-15.

[16] N Langer, AH Bhat and P Agarwal. Neural-network-based space-vector pulse-width modulation for capacitor voltage balancing of three phase three-level improved power quality converter. IET Power Electron. 2014; 7, 973-83.

[17] TK Vrana and S Energi. Review of HVDC component ratings: XLPE cables and VSC converters. In: Proceedings of the 2016 IEEE International Energy Conference, Leuven, Belgium, 2016.

[18] J Song-Manguelle, T Maja Harfman, S Chi, SK Gunturi and R Datta. Power transfer capability of HVAC Cables for Subsea Transmission and Distribution Systems. IEEE Trans. Ind. Appl. 2014; 50, 2382-91.

[19] C Wenzhuan, Y Feng, L Xiongwei and J Whitty. Analysis of the passive yaw mechanism of small horizontal-axis wind turbines. In: Proceedings of the 2009 World Non-Grid-Connected Wind Power and Energy Conference, Nanjing, China, 2009.

[20] AK Verma, B Singh and DT Shahani. Grid interfaced solar photovoltaic power generating system with power quality improvement at AC mains. In: Proceedings of the 2012 IEEE Third International Conference on Sustainable Energy Technologies (ICSET), Kathmandu, Nepal, 2012.

[21] Y Ling and X Cai. Rotor current dynamics of doubly fed induction generators during grid voltage dip and rise. Int. J. Electr. Power Energ. Syst. 2013; 44, 17-24.

[22] JL Elizondo, A Olloqui, M Rivera, ME Macias, O Probst, OM Micheloud and J Rodríguez. Modelbased predictive rotor current control for grid synchronization of a DFIG driven by an indirect matrix converter. IEEE J. Emerg. Sel. Top. Power Electron. 2014, 2, 715-26.

[23] X Zhen, Z Xing, Y Shuying, L Qin and Z Wenfeng. Study on control strategy of maximum power capture for DFIG in wind turbine system. In: Proceedings of the $2^{\text {nd }}$ International Symposium on Power Electronics for Distributed Generation Systems, Hefei, China, 2010, p. 110-5.

[24] L Zhan, X Jin and L Zhang. An improved grid synchronization control of doubly-fed induction generator. In: Proceedings of the 2012 Asia-Pacific Power and Energy Engineering Conference, Shanghai, China, 2012, p. 1-5.

[25] S Xiao, G Yang, H Zhou and H Geng. An LVRT control strategy based on flux linkage tracking for DFIGBased WECS. IEEE Trans. Ind. Electron. 2013; 60, 2820-32.

[26] K Sarker, D Chatteriee, Goswami and SK Goswami. An optimized co-ordinated approach for harmonic minimization of doubly fed induction generator connected micro-grid system. In. J. Electron. Power Energ. Syst. 2015; 64, 58-70. 
http://wjst.wu.ac.th

[27] H Geng, C Lui and G Yang. LVRT capability of DFIG-based WECS under asymmetrical grid fault condition. IEEE Trans. Ind. Electron. 2013; 60, 2495-9.

[28] LJ Camurça. J Lago and ML Heldwein. High efficiency wind energy conversion system based on the Three-Level Delta-Switch T-Type Converter and PMSG Model Based loss minimization. In: Proceedings of the 2015 IEEE $13^{\text {th }}$ Brazilian Power Electronics Conference and $1^{\text {st }}$ Southern Power Electronics Conference, Fortaleza, Brazil, 2015.

[29] DG Montoya, CA Ramos-Paja and R Giral. Improved design of sliding-mode controllers based on the requirements of MPPT techniques. IEEE Trans. Power Electron. 2016; 31, 235-47.

[30] C Wei, Z Zhang, W Qiao and L Qu. An adaptive network-based reinforcement learning method for MPPT control of PMSG wind energy conversion systems. IEEE Trans. Power Electron. 2016; 31, 7837-48.

[31] Q Tang, X Ge, YC Liu and M Hou. Improved switching-table-based DTC strategy for the post-fault three-level NPC inverter-fed induction motor drives. IET Elec. Power Appl. 2018; 12, 71-80.

[32] DG Giaourakis and AN Safacas. Quantitative and qualitative behavior analysis of a DFIG wind energy conversion system by a wind gust and converter faults. Wind Energ. 2015; 19, 527-46.

[33] L Chen, H Chen, Z Shu, G Zhang, T Xia and L Ren. Comparison of inductive and resistive SFCL to robustness improvement of a VSC-HVDC system with wind plants against DC fault. IEEE Trans Appl Supercond. 2016; 26, 1-8.

[34] J Tekobon. 2016, Système multi physique de simulation pour l'étude de la production de l'énergie basée sur le couplage éolien offshore-hydrolien. Thesis. University of Havre, France.

[35] JW Praiselin and JB Edward. A review on impacts of power quality, control and optimization strategies of integration of renewable energy based microgrid operation. Int. J. Intell. Syst. Appl. $2018 ; 11,67-81$. 